\title{
Bioremediation of Diesel Oil Spill by Filamentous Fungus Trichoderma reesei $\mathrm{H002}$ in Aquatic Environment
}

\author{
Tasnia Hassan Nazifa ${ }^{1}$, Mohd Azlan Bin Ahmad ${ }^{1}$, Tony Hadibarata ${ }^{2 *}$, \\ Salmiati $^{3}$, Azmi Aris ${ }^{3}$
}

\author{
${ }^{1}$ Department of Environmental Engineering, Faculty of Civil Engineering, Universiti Teknologi Malaysia, 81310 UTM \\ Skudai, Johor, MALAYSIA \\ ${ }^{2 *}$ Department of Civil and Construction Engineering, Faculty of Engineering and Science, Curtin University, 98009 , \\ Sarawak, MALAYSIA. \\ ${ }^{3}$ Centre for Environmental Sustainability and Water Security, Research Institute for Sustainable Environment, \\ Universiti Teknologi Malaysia, 81310 UTM Skudai, Johor, MALAYSIA.
}

Received 15 March 2018; accepted 12 December 2018, available online 31 December 2018

\begin{abstract}
Bioremediation of aquatic environment could be a response to the oil spills threats. In this paper, Trichoderma reesei H002, a filamentous ascomycete fungus isolated from a polluted site in an orchard garden, Johor, Malaysia, was experimented for its biodegradation ability to degrade diesel oil. Varying nitrogen and carbon sources, $\mathrm{pH}$, agitation on diesel oil by Trichoderma reesei H002 in liquid media were examined to find their impacts on TPHs, alkane, aromatic and NSO fractions of diesel oil degradation. Glucose and yeast extract were the most suitable nutrients for the development of $T$. reesei $\mathrm{H} 002$ and increased the degradation of total petroleum hydrocarbons (TPHs up to $94.78 \%$ at the end of the study (40 days) at $25{ }^{\circ} \mathrm{C}$. The degradation of TPHs were performed by gravimetric analysis and degradation of alkane and aromatic fractions were confirmed by GC-FID analysis. Based on the findings of $T$. reesei $\mathrm{H} 002$ for the biodegradation of diesel oil, it can be proposed that $T$. reesei $\mathrm{H} 002$ can be applied to bioremediate diesel oil spill in aquatic environment, therefore protect the ecosystem.
\end{abstract}

Keywords: Oil spill treatment, Trichoderma reesei H002, bioremediation, TPHs.

\section{Introduction}

Most of the worldwide oil production is transported by aquatic environment specially sea, therefore marine and coastal environments are prominently exposed to accidental oil spill incidents. The detrimental effects after an oil spill are incalculable, not only affecting human health but also threatening environmental ecosystem [9] Once the oil has been released in the environment, oil prevents oxygen penetration and diffusion of light. In addition, its mutagenicity and carcinogenicity has been reported in many literature [8]. Therefore, it needs high priority to find an effective technology for eradicating contaminants to reduce oil pollution.

Nowadays, different techniques like using chemical dispersant or in situ burning are applied for oil removal but they possess ecological, economic or technic drawbacks: for example, using dispersant it only separate oil into another phase which is difficult to remove from the environment and sometimes the dispersants are seen more harmful than the spilled oil itself [14]. Such drawbacks can be overcome by microbial removal which avoid recontamination by secondary contaminants originated from chemical and physical remediation process. However, diesel like heavy fuel ranged from C8 to $\mathrm{C} 25$ are recalcitrant to remove naturally or in aerobic condition under limited nutrients [5]. Therefore, bioengineers and microbiologists working in related fields are facing a challenge to develop technologies which will ensure a good relationship among relevant microorganism and hydrocarbon and thereby adding the inadequate nutrients [9].

The term bioremediation means applying microorganism which are capable to degrade toxic pollutants for restoration of any polluted site [9]. Mostly microorganism like fungi and bacteria are used based on their ability to use hydrocarbon oil including its derivatives as carbon source. Their robustness and adaptation skills to withstand in extreme environments, lead them towards bioremediation process. Oil spill bioremediation is a common practice for treatment of the contaminated terrestrial environments [10]. However, the knowledge regarding marine oil spill treatment is still not smooth and its majority focused on the prokaryotic organisms. In addition, nutrients supply play an important role in biodegradation by microorganisms. Supply of nutrients like carbon or nitrogen source have been reported to enhance the biodegradation rate due to accelerated production of enzymatic action [6, 12]. Fungal species Trichoderma belong to filamentous group of fungi classified as a part of Ascomycetes. This species of fungi is distributed in grassland, agricultural system, 
deserts, forests as well as aquatic ecosystems. Also, nutrient requirements are considered low as these fungi can survive in adverse conditions [2]. A study done by [4], showed that few Trichoderma species have the ability to degrade some of the fractions of petroleum hydrocarbons. Hence, it can be say that saturated hydrocarbons are easily degraded than that of PAHs. For example, Trichoderma S019 strain have the ability to degrade n-eicosane about $73 \%$ with the addition of glucose as subsidiary carbon source [7]. Trichoderma species like T.inhamatumson, T. longibrachiatum or $T$. harizanium have been reported to withstand $100 \mathrm{mg} / \mathrm{L}$ of pyrene or phenanthrene. Moreover, fungi degrading PAHs are reported recently, PAHs like benzo(a) fluoranthene, benzo(a)anthracene, benzo(a)pyrene, chrysene are reported to be degraded by the species Trichoderma [2]. Unfortunately, the ability of the filamentous fungal species associated to oil spill treatment in aquatic environment is limited, being the key topic of few researchers $[1,3]$.

The aim of this research is to investigate diesel oil spill treatment by fungi Trichoderma reesei $\mathrm{H} 002$ in marine environment. To find out the optimum treatment for oil spill, a $\mathrm{pH}$ ranges from 4 to 8 and agitation ranges from $80 \mathrm{rpm}$ to $120 \mathrm{rpm}$ has been studied. In addition, three carbon sources (galactose, fructose, glucose), four nitrogen sources (yeast extract, ammonium nitrate, ammonium chloride, ammonium sulphate) and different concentration of oil were applied for better understanding the role of fungal species in marine oil spill incidents.

\section{Materials and Methods}

\section{Fungi}

A filamentous fungus designated as $\mathrm{H} 002$ was isolated from a contaminated site in UTM orchard area, Johor, Malaysia and stored in a refrigerator to maintain their growth. Prior to use, tissue of the collected fungi was cut into small piece and cultured on malt extract agar (MEA). Based on $18 \mathrm{~s}$ rRNA identification and macroscopic morphological characteristics, phylogenetic tree was constructed, and $\mathrm{H} 002$ was classified as belonging to the Trichoderma reesei (Fig 1).

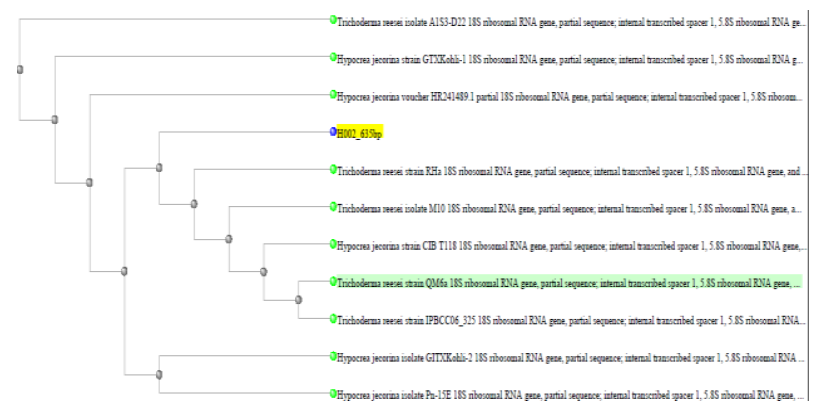

Fig 1. Phylogenetic tree of Trichoderma reesei $\mathrm{H} 002$ species.

\section{Chemicals and Reagents}

MEA was procured from Difco (Detroit, USA). Glucose, yeast extract as well as other nutrients and chemicals were highly analytical grade and were supplied by Sigma Aldrich supplier company from Milwaukee, USA. From BHPetrol station in skudai, Johor, diesel oil was bought. Physical and chemical characteristics of diesel oil are listed in Table 1.

\section{Fungal Inoculum and Culture Conditions}

The strain of $T$. reesei $\mathrm{H} 002$ was maintained on MEA containing $20 \mathrm{~g} / \mathrm{L}$ glucose, $20 \mathrm{~g} / \mathrm{L}$ malt extract agar, $300 \mathrm{mg} / \mathrm{L}$ chloramphenicol to avoid bacterial growth and $4 \mathrm{~g} / \mathrm{L}$ diesel oil in a glass petri dish at a dark place at room temperature and observed on daily basis for seven days. To study biodegradation of oil, three agar plugs of fungal inoculum were cut out from MEA plate fungal mycelium and transferred to liquid medium containing 20 $\mathrm{g} / \mathrm{L}$ of both glucose, yeast extract and $300 \mathrm{mg} / \mathrm{L}$ of chloramphenicol. All the reagents were mixed with distilled water until it made a final volume of $30 \mathrm{ml}$ in a 100-ml flask. After 4-5 days of incubation to get a homogenous distribution of fungal growth, finally a predetermined concentration of diesel oil containing $0.2 \%$ Tween 80 (1000 ppm-4000 ppm) has been added and kept in incubation or at $100 \mathrm{rpm}$ for 20 and 40 days at room temperature. Each sample flask was prepared in triplicate to get an accurate result. All glass wares including liquid medium was autoclaved for $20 \mathrm{~min}$ at $121{ }^{0} \mathrm{C}$. In addition, control flask containing diesel oil without inoculum was also maintained parallelly.

Table 1. Physical and chemical characterization of diesel oil.

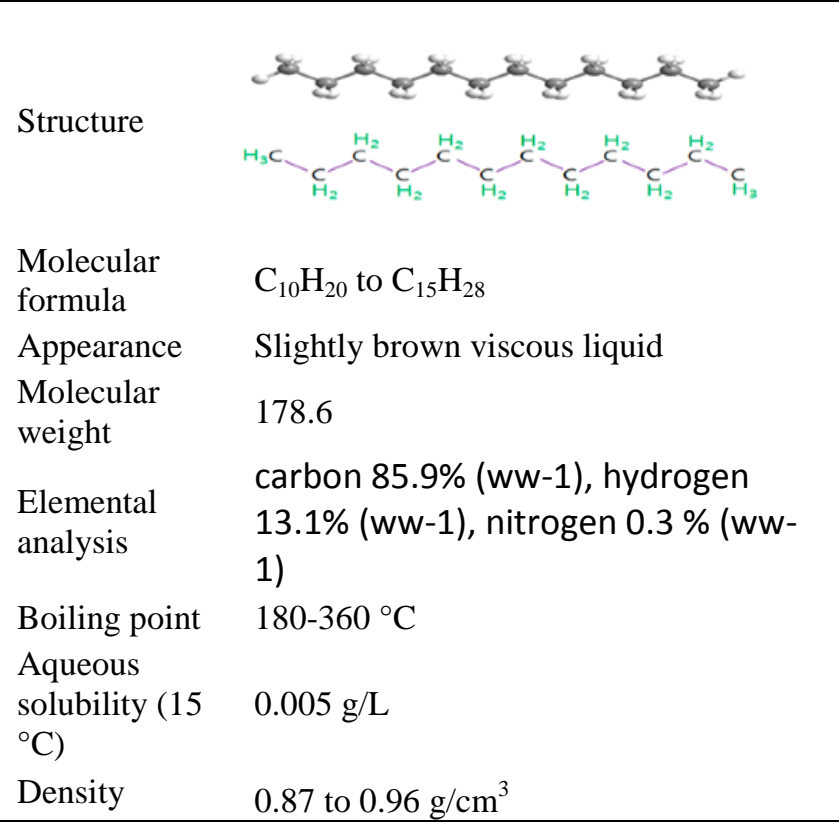

\section{TPH quantification}

Samples were withdrawn at zero day (just before the bioremediation started), 10-day, 20 days and 40 days. Extraction procedure was followed from the method 
provided by [9]. Briefly, TPH content in each cultured flask was extracted by equal volume of hexane followed by dichloromethane and finally chloroform. These three extracts volume were dried using a rotary evaporator and nitrogen stream until it gets complete dry. Then amount of remaining TPH was calculated gravimetrically. After gravimetric calculation, remaining $\mathrm{TPH}$ was divided into alkane fraction, aromatic as well as NSO fractions using silica gel loaded column. Alkane and aromatic fractions were eluted $100 \mathrm{ml}$ hexane and $100 \mathrm{ml}$ toluene. Lastly, the NSO fraction part was eluted by $200 \mathrm{ml}$ of $1: 1$ methanol and chloroform. The aromatic and alkane fraction were analyzed by GC-FID (Agilent), injecting 1 $\mu 1$ of each solvent. The temperature program was set to $350 \mathrm{C}$ for $2 \mathrm{~min}$ then rise to $2900 \mathrm{C}$ at a rate of $120 \mathrm{C} / \mathrm{min}$ covering a total run of $24 \mathrm{~min}$. Gravimetric calculation of degradation of TPH was done by following equation,

$\%$ Degradation of TPHs $=\left(\mathrm{W}_{0}-\mathrm{W}_{\mathrm{t}}\right) / \mathrm{W} 0 \mathrm{X} 100 \%$

$\mathrm{W}_{0}$ and $\mathrm{W}_{\mathrm{t}}$ are the weight of TPHs in dry round bottom flask at 0 day and after treatments.

\section{Result and Discussion}

The lowest rate $(51 \%)$ of degradation of TPHs (mg/30 mL liquid media) was observed at highest concentration of diesel oil (4000 ppm) while 67\%, 80\%, $85 \%$ and $95 \%$ degradation of TPHs were observed at 3000 ppm, 2000 ppm, 1500 ppm and 1000 ppm oil (data not shown). Hence, a natural trend is seen showing the decrease of degradation with the increase of initial concentration of diesel oil. Alkane and aromatic fractions collected from 1000 ppm diesel oil by GC analysis after silica fractionation loaded on column is shown in Fig 2 (A, B, C , D). Table 2 summarizes all parameters of batch culture.
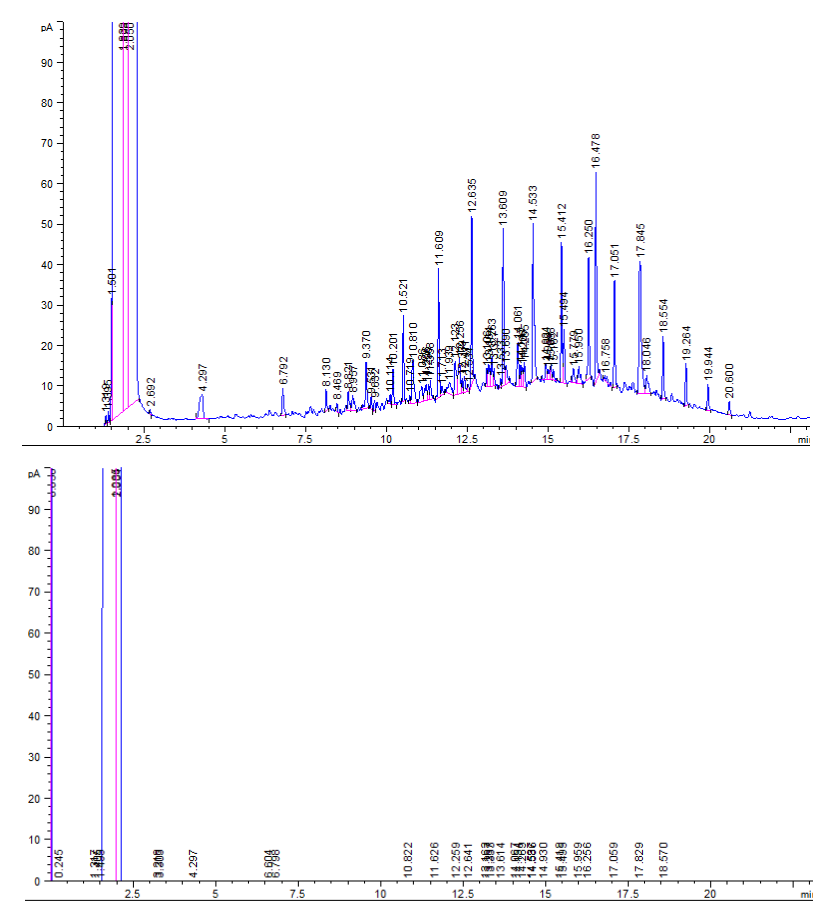

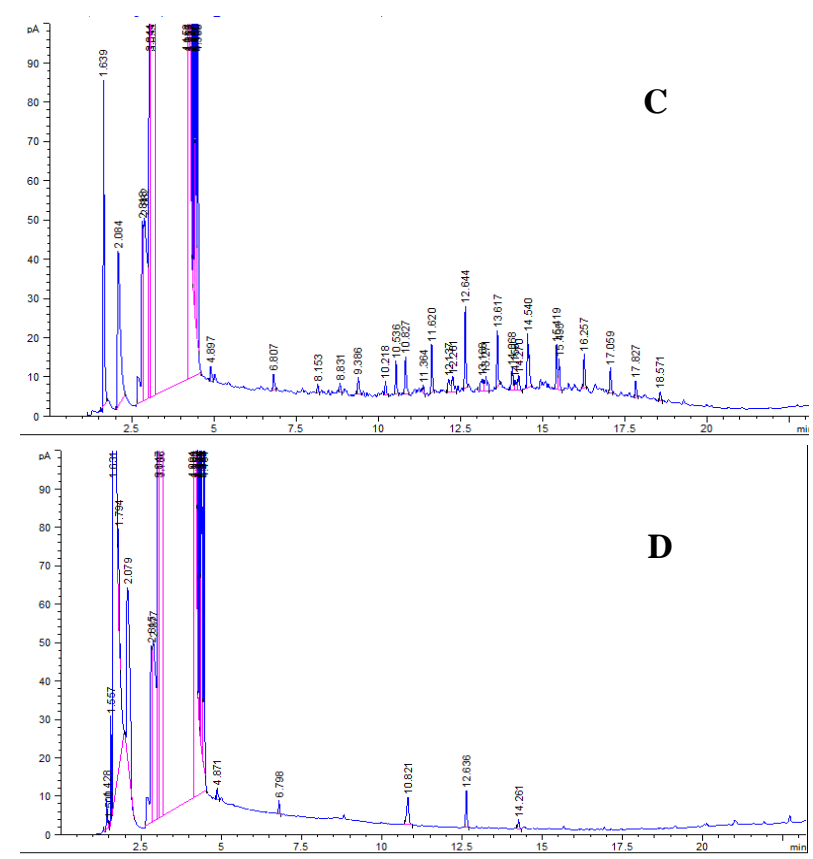

Fig 2. Degradation of alkane at 0 day (A), after 40 days (B), aromatic at 0 day (C) and after 40 days (D).

\subsection{Effect of $\mathrm{pH}$}

Regulation of $\mathrm{pH}$ in liquid medium is practically crucial since it affects the enzyme activity including biodegradation procedure by $T$. reesei $\mathrm{H} 002$. In our experiment, $\mathrm{pH} \mathrm{4,} \mathrm{5,} 6$ and 8 were studied (Fig. 3A). In room temperature, highest degradation of TPH was found at a range of $\mathrm{pH} 5$ to 6 at the end of 40 day. However, at $\mathrm{pH} 8$, the degradation was seen to reduce (52\% only). Similar optimum value of $\mathrm{pH}(\mathrm{pH} 5.5)$ was maintained constant to degrade crude oil and some aromatic compounds by Trichoderma strain [2].

\subsection{Effect of Agitation}

To figure out the optimum agitation limit, three distinct conditions with agitation $(80,100$ and $120 \mathrm{rpm})$ were maintained placing the inoculated flask on mechanical shaker. From the graph In Fig. 3B, it is seen that at higher shaking rate $(120 \mathrm{rpm})$ the degradation of $\mathrm{TPH}$ is lowest (only 56\%) and projecting $84.4 \%$ degradation at $100 \mathrm{rpm}$. Sufficient agitation enhances the distribution of carbon and nitrogen source in liquid media which helps for the proper growth of inoculum, however, excessive agitation causes mycelium shearing leading to decrease in biomass yield [18].

\subsection{Effect of Carbon Source}

Carbon source is one of the fundamental nutrients for fungal growth. In oil spill bioremediation process, hydrocarbon oil can be used as sole carbon source [6] or with the presence of other carbon sources like glucose [9]. In this study, three different carbon sources like glucose, galactose and fructose were applied with yeast 
extract as nitrogen source. Fig. 3D suggests the effect of carbon sources in an order like glucose (94.78\%) > galactose $(71.5 \%)>$ fructose $(60.5 \%)$ at the end of 40 days culture.

\subsection{Effect of Nitrogen Source}

The highest degradation of oil was observed by using yeast extract as nitrogen source comprising more than 94\% removal of TPH of diesel. Degradation rate after 40 days can be arranged in an order like yeast extract $(94.8 \%)>$ ammonium chloride $(84.4 \%)>$ ammonium sulphate $(70 \%)>$ ammonium nitrate $(51 \%)$ (Fig 3C). [13] reported the degradation of olive oil mill effluent by fungi $P$. citrinopileatus was best observed in the presence of yeast extract due to increase laccase enzyme production. A comparison showing diesel oil degradation by other species is listed in Table 3.
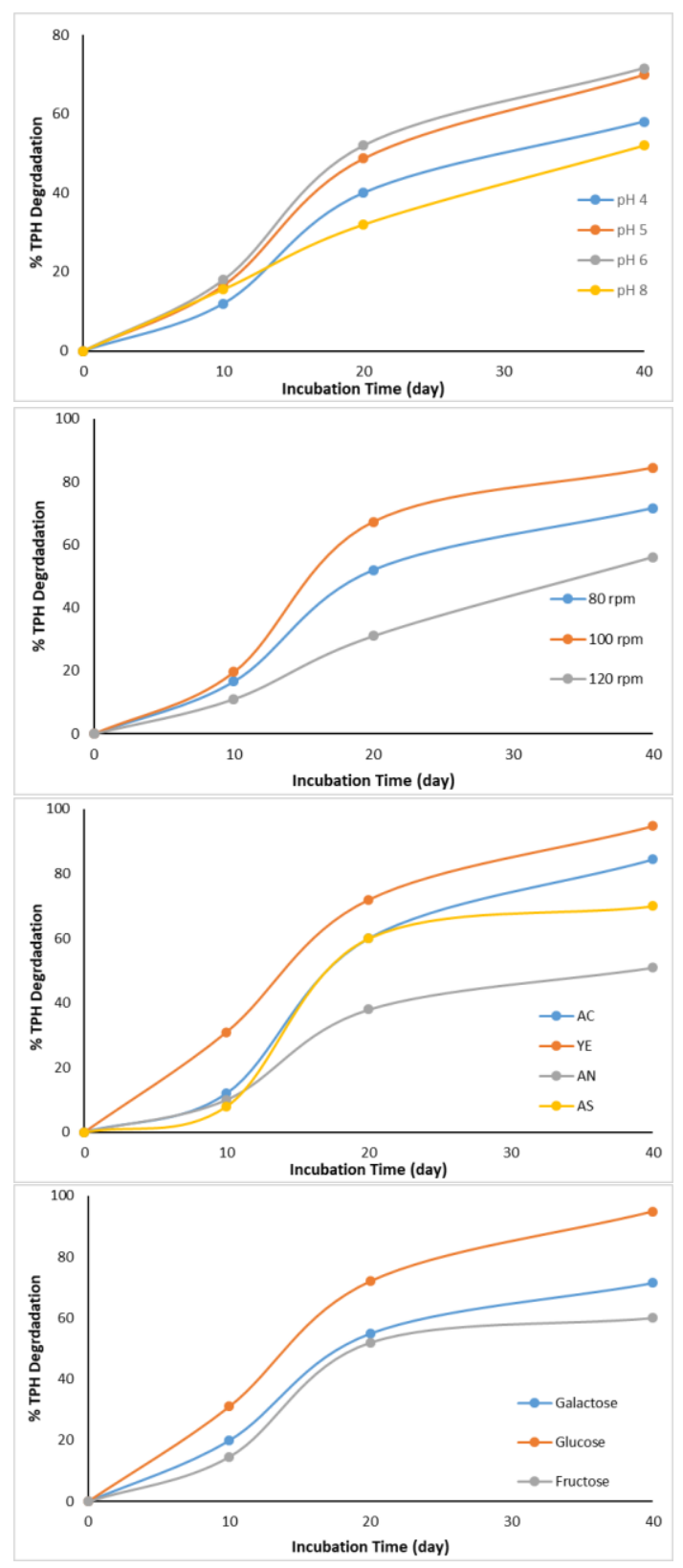

Fig. 3 Effect of $\mathrm{pH}$ (A), agitation (B), nitrogen source (C), carbon source (D) on 1000 ppm diesel oil. AC: ammonium chloride, YE: yeast extract, $\mathrm{AN}$ : ammonium nitrate, AS: ammonium sulphate.

Table 2. Summarizes for all experiments of batch culture.

\begin{tabular}{lcccc}
\hline Parameters & $\begin{array}{c}\text { Initial } \\
\mathrm{pH}\end{array}$ & Agitation & $\begin{array}{c}\text { Nitrogen } \\
\text { Source }\end{array}$ & $\begin{array}{c}\text { Carbon } \\
\text { Source }\end{array}$ \\
\hline $\begin{array}{l}\text { Effect of } \\
\text { initial pH }\end{array}$ & 4 to 8 & 80 & AC & Glucose \\
$\begin{array}{l}\text { Effect of } \\
\text { agitation }\end{array}$ & 6 & 80 to 120 & AC & Glucose \\
$\begin{array}{l}\text { Nitrogen } \\
\text { source }\end{array}$ & 6 & 100 & $\begin{array}{c}\text { AC, YE, } \\
\text { AN, AS }\end{array}$ & Glucose \\
$\begin{array}{l}\text { Carbon } \\
\text { source }\end{array}$ & 6 & 100 & YE & $\begin{array}{c}\text { Glucose, } \\
\text { Galactose, } \\
\text { Fructose }\end{array}$ \\
\hline
\end{tabular}

* AC: ammonium chloride, YE: yeast extract, AN: ammonium nitrate, AS: ammonium sulphate.

Table 3. Some species used for degradation of diesel oil.

\begin{tabular}{lcl}
\hline \multicolumn{1}{c}{ Species } & $\begin{array}{c}\% \\
\text { Degradation }\end{array}$ & \multicolumn{1}{c}{ Source } \\
\hline $\begin{array}{l}\text { Cladosporium } \\
\text { Trichosporon } \\
\text { asahii }\end{array}$ & $34 \%$ & {$[10]$} \\
$\begin{array}{l}\text { T. longibrachiatum } \\
\text { Evx } 1\end{array}$ & $95 \%$ & {$[11]$} \\
$\begin{array}{l}\text { Trichoderma } \\
\text { reesei } \text { H002 }\end{array}$ & $54 \%$ & {$[12]$} \\
\hline
\end{tabular}

\section{Conclusion}

Oil spills are posing immense threat for wildlife biodiversity and aquatic ecosystem and the appropriate use of microorganisms capable to biodegrade this hydrocarbon oil constituents have demanded a real challenge for future researches. Until recently, Trichoderma reesei species fungi had been overlooked despite their potential hydrocarbon degradative abilities. The biodegradation ability of the $T$. reesei $\mathrm{H} 002$ has considerably boosted by optimizing physio-chemical parameters. Filamentous fungus $T$. reese $i \mathrm{H} 002$ degraded more than $90 \%$ TPHs of diesel oil of $1000 \mathrm{ppm}$ with agitation $100 \mathrm{rpm}, \mathrm{pH} 6$ and in the presence of glucose and yeast extract. This encouraging result established that $T$. reesei $\mathrm{H} 002$ is an effective candidate for the bioremediation of diesel oil spill in ocean and therefore, help to protect ecosystem. Further study to identify the excreted fungal enzymes that are responsible for degradation of oil is needed.

\section{Acknowledgement}

This work has been supported by PRGS No. 4L675, UTM, Malaysia. 


\section{Reference}

[1] Al-Nasrawi, H. Biodegradation of crude oil by fungi isolated from Gulf of Mexico. $J$ Bioremed Biodegrad, Volume 3(04), (2012).

[2] Argumedo-Delira, R., Alarcón, A., Ferrera-Cerrato, R., Almaraz, J. J., \& Peña-Cabriales, J. J. Tolerance and growth of 11 Trichoderma strains to crude oil, naphthalene, phenanthrene and benzo [a] pyrene. Journal of environmental management, Volume 95, (2012), pp S291-S299.

[3] Atlas, R. M. Microbial hydrocarbon degradationbioremediation of oil spills. Journal of Chemical Technology and Biotechnology, Volume 52(2), (1991), pp 149-156.

[4] Chaineau, C., Morel, J., Dupont, J., Bury, E., \& Oudot, J. Comparison of the fuel oil biodegradation potential of hydrocarbon-assimilating microorganisms isolated from a temperate agricultural soil. Science of the Total Environment, Volume 227(2), (1999), pp 237-247.

[5] Cheng, Y., Wang, L., Faustorilla, V., Megharaj, M., Naidu, R., \& Chen, Z. Integrated electrochemical treatment systems for facilitating the bioremediation of oil spill contaminated soil. Chemosphere, Volume 175, (2017), pp 294-299.

[6] Crisafi, F., Genovese, M., Smedile, F., Russo, D., Catalfamo, M., Yakimov, M., . . . Denaro, R. Bioremediation technologies for polluted seawater sampled after an oil-spill in Taranto Gulf (Italy): A comparison of biostimulation, bioaugmentation and use of a washing agent in microcosm studies. Marine Pollution Bulletin, Volume 106(1), (2016), pp 119126.

[7] Hadibarata, T., \& Tachibana, S. Microbial degradation of n-eicosane by filamentous fungi. Interdisciplinary studies on environmental chemistry and environmental research in Asia.(Eds. Y. Obayashi, T. Isobe, A. Subramanian, S. Suzuki and S. Tanabe), Terrapub, Tokyo, (2009), pp 323-329.

[8] Huang, M., Mesaros, C., Zhang, S., Blair, I. A., \& Penning, T. M. Potential Metabolic Activation of a Representative C2-Alkylated Polycyclic Aromatic Hydrocarbon 6-Ethylchrysene Associated with the Deepwater Horizon Oil Spill in Human Hepatoma (HepG2) Cells. Chemical research in toxicology, Volume 29(6), (2016), pp 991.

[9] Kristanti, R. A., Hadibarata, T., Toyama, T., Tanaka, Y., \& Mori, K. (2011). Bioremediation of crude oil by white rot fungi Polyporus sp. S133. Journal of microbiology and biotechnology, Volume 21(9), (2011), pp 995-1000.

[10] Marco-Urrea, E., Garcia-Romera, I., \& Aranda, E. (2015). Potential of non-ligninolytic fungi in bioremediation of chlorinated and polycyclic aromatic hydrocarbons. New biotechnology, Volume 32(6), (2015), pp 620-628.
[11]Patowary, K., Patowary, R., Kalita, M. C., \& Deka, $\mathrm{S}$. Characterization of biosurfactant produced during degradation of hydrocarbons using crude oil as sole source of carbon. Frontiers in microbiology, Volume 8, (2017).

[12] Yanto, D. H. Y., Hidayat, A., \& Tachibana, S. Periodical biostimulation with nutrient addition and bioaugmentation using mixed fungal cultures to maintain enzymatic oxidation during extended bioremediation of oily soil microcosms. International biodeterioration \& biodegradation, Volume 116, (2017), pp 112-123.

[13]Zerva, A., Zervakis, G. I., Christakopoulos, P., \& Topakas, E. Degradation of olive mill wastewater by the induced extracellular ligninolytic enzymes of two wood-rot fungi. Journal of environmental management, Volume 203, (2017), pp 791-798.

[14]Zheng, M., Ahuja, M., Bhattacharya, D., Clement, T. P., Hayworth, J. S., \& Dhanasekaran, M. Evaluation of differential cytotoxic effects of the oil spill dispersant Corexit 9500. Life sciences, Volume 95(2), (2014), pp 108-117.

[15] You-Qing, L.I., Hong-Fang, L. I, U., Zhen-Le, T. I. A. N., Li-Hua, Z. H. U., Ying-Hui, W. U., \& HeQing, T. A. N. G. Diesel Pollution Biodegradation: Synergetic Effect of Mycobacterium and Filamentous Fungi11This work was supported by the grant from the National Foundation of Natural Science in China (No. 30571536). Biomedical and Environmental Sciences, Volume 21(3), (2008), pp 181-187.

[16] Chandran, P. R. E. E. T. H. Y., \& Das, N. I. L. A. N. J. A. N. A. Biosurfactant production and diesel oil degradation by yeast species Trichosporon asahii isolated from petroleum hydrocarbon contaminated soil. Int J Eng Sci Technol, Volume 2(12), (2010), pp 6942-6953.

[17] Andreolli, M., Lampis, S., Brignoli, P., \& Vallini, G. (2016). Trichoderma longibrachiatum Evx1 is a fungal biocatalyst suitable for the remediation of soils contaminated with diesel fuel and polycyclic aromatic hydrocarbons. Environmental Science and Pollution Research, Volume 23(9), (2016), pp 91349143. 